Werner Wunderli ${ }^{1}$, Sophie Chappuis ${ }^{1}$, Heidi Wunderli ${ }^{2}$

' Central Laboratory of Virology, University Hospital of Geneva

2 Department of Pharmacy, Federal Institute of Technology, Zurich

\title{
World-wide surveillance of influenza
}

\section{Summary}

Influenza epidemics and pandemics resulting in excess mortality are due to various influenza viruses, in which through the accumulation of mutations the structure changes. A world-wide surveillance has been set up for early detection of new influenza virus strains and of epidemics or pandemics resulting thereof. Basing on such data the World Health Organisation (WHO) issues recommendations to Public Health authorities on the most efficient means for prevention.

\section{Characteristics of the virus}

A number of epidemics caused by influenza has been described in historical times. Hippocrates reported in $412 \mathrm{BC}$ about such an epidemic. Later on, it was observed that outbreaks occurred frequently but at irregular intervals. Historical data were reviewed by Noble and in his review, several characteristics of influenza epidemics and pandemics were pointed out: 1 . They appear at irregular intervals; 2 . They vary in severity and they usually cause mortality in the elderly; 3 . The epidemics often come from Asia. The virus shows some peculiar properties which allows it to cause epidemics under certain conditions. Subsequently some characteristics will be summarized, in order to better understand this phenomenon.

\section{Nomenclature}

Influenza $\mathrm{A}$ and $\mathrm{B}$ viruses belong to the family of the Orthomyxoviruses. They can be distinguished from each other by differences in certain proteins like nucleoproteins and matrix proteins. Influenza viruses are highly variable. Therefore, a system had to be established to be able to distinguish the variants from each other. The current system includes the host of origin, geographical location of the first isolation, strain number, and year of isolation. The description of the types of surface proteins is given in parenthesis. To give an example:

\section{A/Swine/Iowa/15/30 $\left(\mathrm{H}_{1} \mathrm{~N}_{1}\right)$}

This represents an influenza $A$ virus which has been isolated from a swine in 1930 in Iowa. It was the $15^{\text {th }}$ isolate of that particular year.
$\mathrm{H}_{1}$ and $\mathrm{N}_{1}$ are the types of the two surface proteins present in this virus. The host is not indicated if the virus strain detected is of human origin. As we will see in the following it is very important to distinguish the different variants in particular for the production of vaccines.

\section{Structure of the virus}

Electron microscopy shows influenza viruses as spherical, irregularly shaped, with a diameter of about $120 \mathrm{~nm}$. The virus constitutes a lipid bilayer, containing the typical surface glycoproteins hemagglutinin (HA) and neuraminidase (NA) (Fig. 1). These proteins form a layer of spikes projecting radially outward. Three types of $\mathrm{HA}\left(\mathrm{H}_{1}\right.$, $\left.\mathrm{H}_{2}, \mathrm{H}_{3}\right)$ and two types of NA $\left(\mathrm{N}_{1}\right.$, $\mathrm{N}_{2}$ ) are found in viruses which can infect humans. These two surface proteins are essential for the process of infection and virus release. Normally, these proteins are detectable on the surface of infected cells, before the virus buds through the membrane, taking a piece of the lipid bilayer as an envelope containing the two surface proteins.

In cells infected in vitro, the viral hemagglutinin can be detected on the cell surface by a specific labeled antibody (Fig. 2a) before the virus 


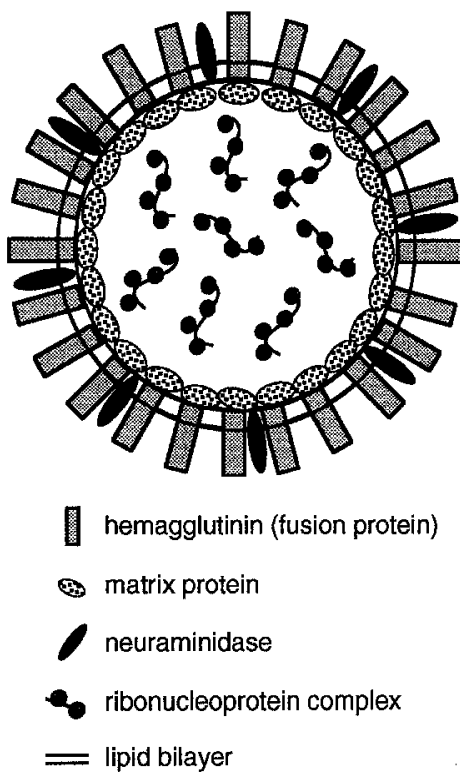

Figure 1. Influenza virus (schematic representation).

is released. A vertical cut through the cell layer shows that the viral protein can be detected on the surface of the cell (Fig. 2a, lower part). This is also the case in vivo.

Within the lipid envelope, there is the matrix protein, containing eight single-stranded RNA molecules. The segmentation of the viral genome is an important feature by which the virus can modify its surface.

Nature of the antigenic drift and antigenic shift

As described, the virus needs the two surface glycoproteins to infect efficiently its host cell. But how does the virus manage to change the structure of the proteins without loosing its infectivity? Different mechanisms have been found. One is the so called antigenic drift. Through the accumulation of point mutations in certain regions of the genome coding for the hemagglutinin, amino acid substitutions can occur. Through the accumulation of such mutations, the protein can gradually change its structure over time. In other words, antibodies which were formed
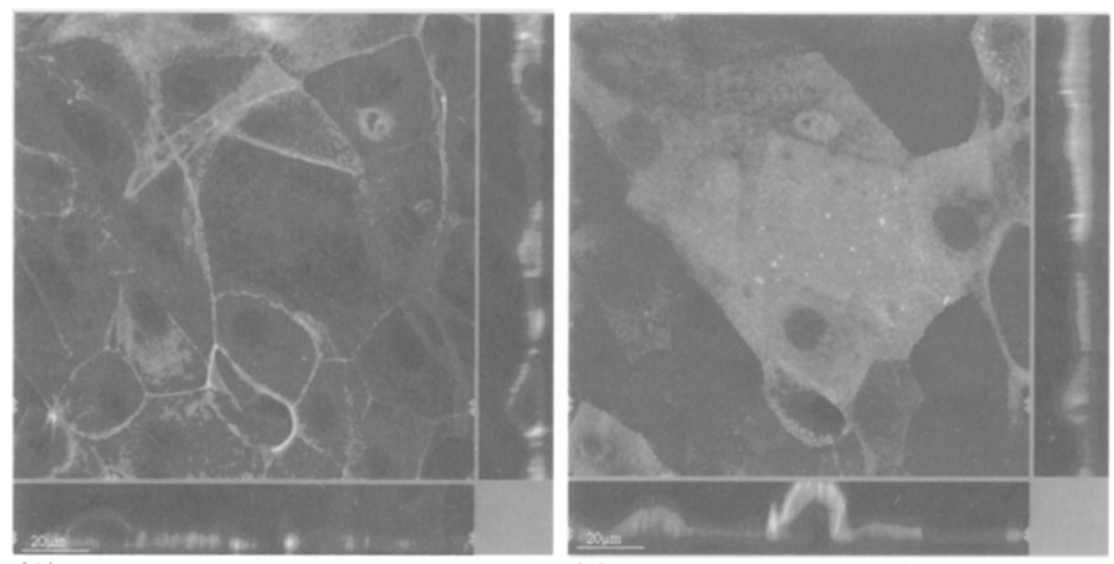

(A)

(B)

Figure 2. $M D C K$ cells infected with influenza A/PR/8/34 $\left(H_{7} N_{7}\right)$ virus. Confocal laser scanning microscopy picture taken $23 \mathrm{~h}$ after infection. (A) The structural protein actin is labeled with fluorescent phalloidin to show the morphology of the MDCK cells. (B) The same area as in (A) is shown with fluorescently labeled hemagglutinin (antibody labeling). The hemagglutinin appears in the perinuclear area and at the cell surface of infected cells.

against an older variant of the virus will not be able to bind or bind less efficiently to the surface proteins of a new variant. Neuraminidase is the second spike protein of the virus. The gene which codes for the neuraminidase is also subjected to an antigenic drift, and it is believed that the nature of the changing mechanism is the same. Through the follow up of virus strains over time, one can see that antibodies formed against older strains will gradually become inefficient. This is one of the reasons why the composition of the vaccine has to be adapted continuously.

Another much more drastic change was discovered. Strains with such principal changes were much more pathogenic, and under certain conditions severe pandemics occurred. Analysis of strains causing pandemics showed that much more substantial changes could be detected. Against these strains, apparently little or no herd immunity existed and this was the reason for the rapid and efficient transmission in the population. But what is the mechanism? Theoretically it is possible that a host is infected with two different virus strains. Under such conditions, and because the genome segments are not linked together, it is possible that the segments of the two distinct strains are mixed and arbitrarily distributed into the virus progeny. Therefore, the surface proteins can be coded from genomes coming from the two parent strains. Under what conditions can such a drastic change occur? As we know, there is a large reservoir of animal influenza viruses with different properties, in particular viruses isolated from birds. However these strains can not directly infect humans. An exchange of a genome is only thinkable if there is a common host. That means a host must exist which can be infected with both types of viruses. The only situation known today is in swine. These animals can be infected with both types of viruses, namely from humans and from aquatic birds ${ }^{5}$. After a mixed infection in swine and the exchange of genomes, certain modified variants arise which will be able to infect humans again. A pandemic can arise due to the lack of immunity against such a variant in the population. Apparently this type of event is rare and unpredictable, as 


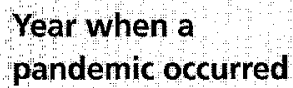

1918

1957

1968

1977

\section{Subtype of the influenza $A$ viruses}

$\mathrm{H}_{1} \mathrm{~N}_{1}$

$\mathrm{H}_{2} \mathrm{~N}_{2}$

$\mathrm{H}_{3} \mathrm{~N}_{2}$

$\mathrm{H}_{1} \mathrm{~N}_{1}$
Severity of the pandemic

devastating

severe

moderate

mild

Table 1. Characteristics of pandemics in our century caused by influenza $A$.

we can see from the frequency of pandemics which occurred in our century (Table 1).

Under certain conditions, additional mechanisms can occur which allow the exchange of only a part of a genome (crossing-over). Through this mechanism the virus can acquire some hidden changes and may cause pandemics which will not have the same degree of severity as it would be with a strain with a totally new surface protein.

Analysis of the different strains which caused pandemics in our century showed that every time one or two of the two surface proteins were completely changed, a pandemic occurred (Table 1). However they occurred at irregular intervals.

\section{Consequences of epidemics} and pandemics

Due to the characteristics of the virus there is a continuous threat of another pandemic. Is it worth to worry about such widespread infections? In fact the well known "Spanish Influenza" from 1918 caused more than 20 million deaths ${ }^{1}$. However, one can observe an excess of mortality not only during pandemics but also during epidemics ${ }^{3}$. For example in the USA, there were 70000 estimated deaths in 1957 (caused by the Asian influenza) and 30000 in 1968 (caused by the Hong Kong virus ${ }^{2}$ ).

Not only the consequences of a pandemic are impressive but also those of an epidemic are considerable. Influenza infects all age groups and the age specific incidence rate is highest in children between one and 14 years. Even if the incidence rate in people older than 60 years ${ }^{2}$ is smaller, the hospitalization rates are highest in the $\geq 65$ and also for the very young ( $\leq$ five years). The death rate is low in children $(2.7$ per 100000$)$

\section{System of influenza surveillance}

and considerably higher ${ }^{2}$ in the 60 years or older (75.9 per 100000). This shows that besides virological aspects, the consequences of an infection justify a world-wide surveillance. Therefore, WHO established a system for the surveillance of the influence virus activity.

In 1947, a group of experts recommended to create an international center for the collection of information about influenza and for the coordination of the laboratory work. The task was given to the National Institute of Medical Research in Mill Hill. Since then the system has been developed and modified, so that the surveillance of influenza can cover the whole world.

Today, the system is based on three different components (Table 2).

- National centers: Each country organizes the surveillance of influenza activity in its area. But the financing of the surveillance is up to the government. Because not all the countries can afford specialized laboratories, the surveillance can not be done everywhere in the same way. The principal aim is to try virus isolations and a preliminary characterization of the isolates. Through this comparison,

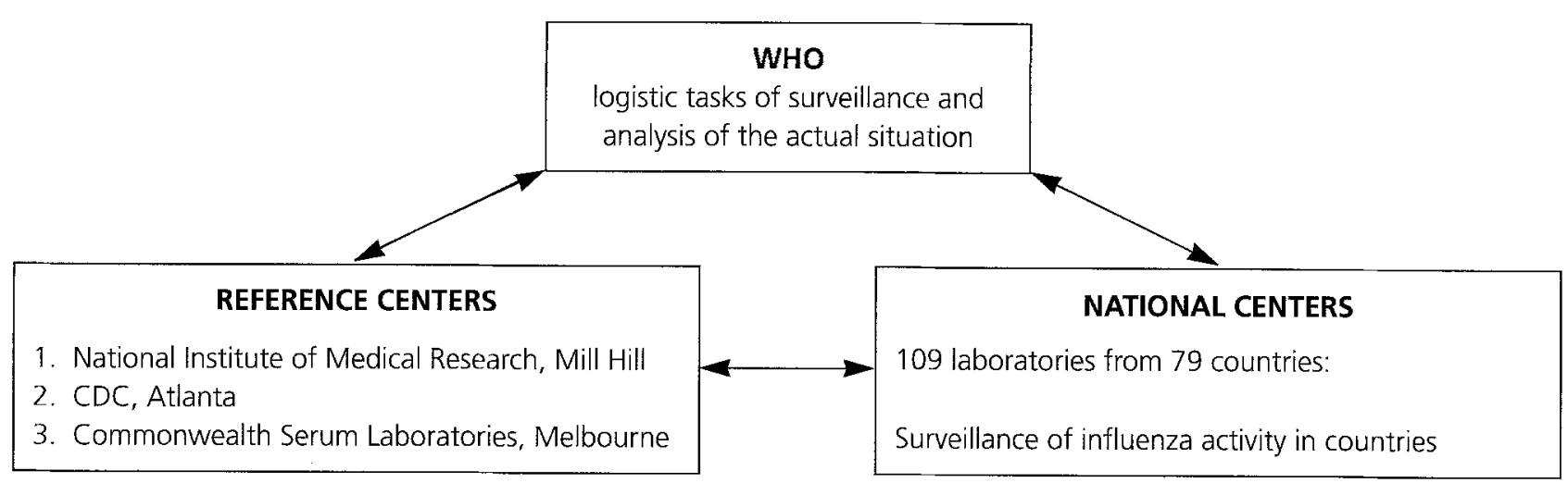

Table 2. System for the world-wide surveillance of influenza. 
already on the national level, important information can be obtained about the frequency of strains in certain regions and countries and also about the pathogenicity of variants.

The results of influenza surveillance and the type of strains detected are transmitted regularly to WHO in Geneva. A selection of virus strains is sent to one of the three reference centers for an extended analysis. National centers often collect more additional data about the epidemiology of an influenza season or an outbreak. These parameters (morbidity, mortality, frequency of consultations for respiratory disease, etc.) are also transmitted to WHO.

- Reference centers have mainly virological tasks. By extended analysis they compare and characterize virus strains sent by the national centers. Beside the classical methods of comparison, they also use characterization techniques by monoclonal antibodies or by genomic analysis.

They also produce reagents for the national centers so that they can do a first characterization. Reference centers also work out scientific and technical recommendations for WHO and for the centers.

- WHO is mainly responsible for the logistic task of the surveillance, as well as the coordination of the exchange of information. Today, not only is the publication of data a major task but a regular update of an Internet home page with the latest epidemiological data has become an important source of information (address: http://www.who.ch).

On the basis of the epidemiological results, WHO, together with experts works out the composition of the vaccine for the next season. Only so the vaccine can stay an efficient means for prevention.

In case of a pandemic, WHO activates a task force, which will continuously analyze the situation and which will give recommendations for the governments.

In Europe, there exists some sort of suborganization. The major aim of this structure is a rapid exchange of information. The organization is in part associated with the government on one side (public health authorities) and on the other side with the vaccine producing industry. Through this, an active exchange of information among the countries is possible. Switzerland is also participating in this European system.

\section{Aims of influenza surveillance}

The organization of a world wide influenza surveillance system is an expensive and rather complicated task. Not all the countries will have the necessary resources to build up an appropriate surveillance system. Because of different limitations and restrictions, surveillance is not done by a standardized system and it is a tricky task for WHO to coordinate such a system and to make a synthesis of the results. Nevertheless it is essential to define what type of information one would like to obtain. Only then can the limited resources be used in an optimal way.

Normally, surveillance should be done all year round. But most of the national centers can only afford to do it during the time where influenza is most prevalent (in the winter of the corresponding hemisphere). For the northern hemisphere, surveillance is normally done between November and April, and in the southern hemisphere between April and October. Seasonal differences are less pronounced in tropial and subtropical areas. Influenza is circulating there all year round but at a lower frequency. Because of the continuous circulation of the virus it would be ideal to do surveillance all year round.
What is the information one can obtain from such a system? They are summarized as follows:

\section{- Detection of epidemics or pande- mics}

Outbreaks caused by influenza should be detected as early as possible. Also the strain or the variant causing the outbreak should be identified very rapidly. With this information the severity of an outbreak can be estimated and further recommendations can be given.

\section{- Properties of the virus}

It may not be evident that the characteristics of a virus causing epidemics is crucial. For several reasons however, a new variant must be identified and characterized as early as possible:

- Only when the virological properties of the virus strain are known can other epidemiological questions be answered properly.

- One must know whether the strain used for the vaccine is sufficiently related to the new variant. Only then one can know whether the actual vaccine is still efficient.

- If the strain is too different (shift), the production of a new vaccine has to be envisaged (monovalent vaccine). The production of a new vaccine can take several months. The decision whether a new virus has the potential to cause a pandemic will never be an easy task.

\section{- Epidemiological details about a particular outbreak}

- An important information about an outbreak will be whether particular age groups are concerned by the infection and if a pronounced influence on the mortality is observed.

- One must know if there is a particular group of persons or patients at high risk due to particularities of the virus.

- Also from virological data, one can conclude whether vaccinated 
persons are more or less protected against the virus.

- Collection of additional information about the epidemics like speed of outspread, centers of infection and in which countries the strain is most prevalent.

- Precautions for prevention

With all the data obtained from the surveillance, WHO will be able to give recommendations to health authorities how to achieve the most efficient prevention.

In general, a global surveillance of the influenza activity has for its major goal to gain time for prevention. Only then can the morbidity, the rates of hospitalization, the mortality and the costs be controlled in case of an outbreak or a pandemic.

\section{Zusammenfassung}

\section{Weltweite Überwachung der Grippe}

Influenza Epidemien oder Pandemien, die zu einer erhöhten Sterblichkeit führen, werden durch verschiedene influenza-Viren verursacht, deren Struktur sich durch die gehäuften Mutationen verändert hat. Um die frühe Erkennung von neuen Influenza-Virusstämmen zu gewährleisten und um die Gefahr allfälliger Epidemien oder Pandemien zu reduzieren, besteht ein weltweites Uberwachungsnetz. Die Weltgesundheitsorganisation WHO veröffentlicht, gestützt auf die durch die Überwachung gewonnenen Daten, Empfehlungen über Massnahmen zur bestmöglichen und effizientesten Prävention.

\section{Résumé}

\section{Surveillance mondiale d'influenza}

Les épidémies et les pandémies d'influenza qui conduisent à une mortalité accrue sont provoquées par divers virus de linfluenza, dont la structure a été modifiée par l'accumulation de mutations. Un réseau de surveillance mondial a été mis sur pied pour assurer la détection prévue de nouvelles souches du virus de l'influenza et pour réduire le danger d'épidemie ou de pandémie. En se basant sur les résultats de cette surveillance l'Organistion Mondiale de la Santé (OMS) publie des recommandations sur les mesures à prendre pour une prévention aussi efficace que possible:

\section{References}

1 Ghendon $Y$. Influenza - its impact and control. Rapp trimest statist sanit mond 1992; 45:306-311.

2 USA Institute of Medicine. New vaccine development establishing priorities 1985-1987-I. Diseases of importance in the United States. Washington D.C., National Academy of Sciences 1985.

3 Ghendon $Y$. Influenza Surveillance. Bulletin of the World Health Organization 1991; 69:509-515.

4 Noble GR. Epidemiological and clinical aspects of influenza. In: Beare A.S. ed. Basic and applied influenza research. Boca Raton FL: CRC Press, 1985: 11-50.

5 Esterday $B C$. Animal Influenza. In: Kilbourne E.D. ed. The Influenza viruses and influenza. Orlando: Academic Press, 1975: 449 - 448.

\section{Acknowledgment}

We gratefully acknowledge the support of M.E. Ramirez for the careful reading and the correction of the manuscript.

\section{Address for correspondence}

Dr. Werner Wunderli

Hôpital Cantonal Universitaire

Laboratoire Central de Virologie

24, rue Micheli-du-Crest

CH-1211 Genève 14 